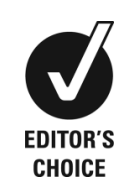
Region, Ilulissat, Greenland

\section{Correspondence to} Dr Trine Dalsgaard Jensen, trinej@hotmail.com

Accepted 1 May 2016

\begin{tabular}{|l|}
\hline To cite: Dalsgaard Jensen T, \\
Penninga L. BMJ Case Rep \\
Published online: [please \\
include Day Month Year] \\
doi:10.1136/bcr-2016- \\
214722 \\
\hline
\end{tabular}

\title{
Appendicitis during pregnancy in a Greenlandic Inuit woman; antibiotic treatment as a bridge-to-surgery in a remote area
}

\author{
Trine Dalsgaard Jensen, Luit Penninga
}

\begin{abstract}
SUMMARY
Appendicitis during pregnancy causes severe diagnostic problems, and is associated with an increase in perforation rate and morbidity compared to that in the normal population. In addition, it may cause preterm birth and fetal loss. In remote areas, appendicitis during pregnancy, besides presenting diagnostic problems, also creates treatment difficulties. In Northern Greenland, geographical distances are vast, and weather conditions can be extreme. We report a case of a Greenlandic Inuit woman who presented with appendicitis during pregnancy. The nearest hospital with surgical and anaesthetic care was located nearly $1200 \mathrm{~km}$ away, and, due to extreme weather conditions, she could not be transferred immediately. She was treated with intravenous antibiotic treatment, and after weather conditions had improved, she was transferred by aeroplane and underwent appendicectomy. She recovered without complications. Our case suggests that appendicitis during pregnancy may be treated with antibiotics in remote areas until surgical treatment is available.
\end{abstract}

\section{CASE PRESENTATION}

A 32-year-old Greenlandic Inuit woman presented with diffuse abdominal pain, nausea and vomiting at 12 weeks of pregnancy. Symptoms started $6 \mathrm{~h}$ after ingestion of raw meat, and she contacted the local hospital. Body temperature was normal, and C reactive protein was slightly increased to $16 \mathrm{mg} / \mathrm{L}$.

Thirty-six hours after initiation, the abdominal pain was localised at the lower right abdomen, which raised the suspicion of appendicitis. On clinical examination, the patient had a temperature of $38.2^{\circ} \mathrm{C}$. The abdomen was painful at the right lower quadrant with local tenderness and peritoneal irritation. Urine examination was normal, and blood analyses showed an elevated white cell count of $16 \times 10^{9} / \mathrm{L}$. C reactive protein was increased to $248 \mathrm{mg} / \mathrm{L}$.

The patient was suspected to have appendicitis and planned for transfer to the nearest hospital where surgical care could be provided. As weather conditions made it impossible to transfer her immediately, she started antibiotic treatment with intravenous ceftriaxone at a dose of $2 \mathrm{~g}$ once daily, and metronidazole at a dose of $0.5 \mathrm{~g}$ three times a day. Antibiotic treatment was initiated $36 \mathrm{~h}$ after initiation of the abdominal pain. After weather conditions had improved, she was transferred by aeroplane to the nearest hospital, where anaesthetic and surgical care could be provided. This regional hospital was located at a distance of nearly $1200 \mathrm{~km}$. After transfer, abdominal ultrasound was performed immediately, and confirmed the diagnosis of appendicitis. Sixty-four hours after initiation of the abdominal pain, open appendicectomy was performed under general anaesthesia, and a gangrenous appendix was removed. No perforation of the appendix had occurred. The postoperative course was without complications. The patient was discharged after 3 days and further pregnancy and delivery were uneventful.

\section{GLOBAL HEALTH PROBLEM LIST}

- Differences in access to healthcare due to geographical circumstances is a well-known global health problem.

- People living in remote areas do not always have direct access to specialised healthcare.

- Treatment of diseases in remote areas may be different from standard treatment due to lack of specialised healthcare.

\section{GLOBAL HEALTH PROBLEM}

Greenland is the largest island in the world and geographical distances are vast; the north-south distance in Greenland is $2650 \mathrm{~km}$, and broadest west-east distance is $1050 \mathrm{~km}$ (figure 1). Moreover, the number of inhabitants is low, and weather conditions can be extreme. Hence, access to healthcare facilities where appropriate treatment can be applied is not always available, or may be delayed. Therefore, established treatment options cannot always be provided. This may necessitate alternative treatment options.

Appendicectomy is the standard treatment option for most patients with acute appendicitis. ${ }^{12}$ Treatment with antibiotics may be a non-invasive alternative treatment option for adult patients with uncomplicated acute appendicitis. Randomised trials and meta-analyses have shown that antibiotic treatment, when compared to surgical appendicectomy, can avoid the need for operation in the majority of patients with uncomplicated appendicitis. However, these trials and meta-analyses have not come out with firm conclusions. Moreover, $\sim 30 \%$ of patients treated with antibiotics undergo appendectomy within 1 year. Additionally, it can be difficult to differentiate between complicated and uncomplicated appendicitis, and this might require CT-scanning or laparoscopy. Nevertheless, studies have shown that the surgical delay occurring in 
Figure 1 Map of Greenland showing vast geographical distances. The patient underwent transfer from Qaanaaq to the Regional hospital in Ilulissat, by aeroplane, a distance of nearly $1200 \mathrm{~km}$.

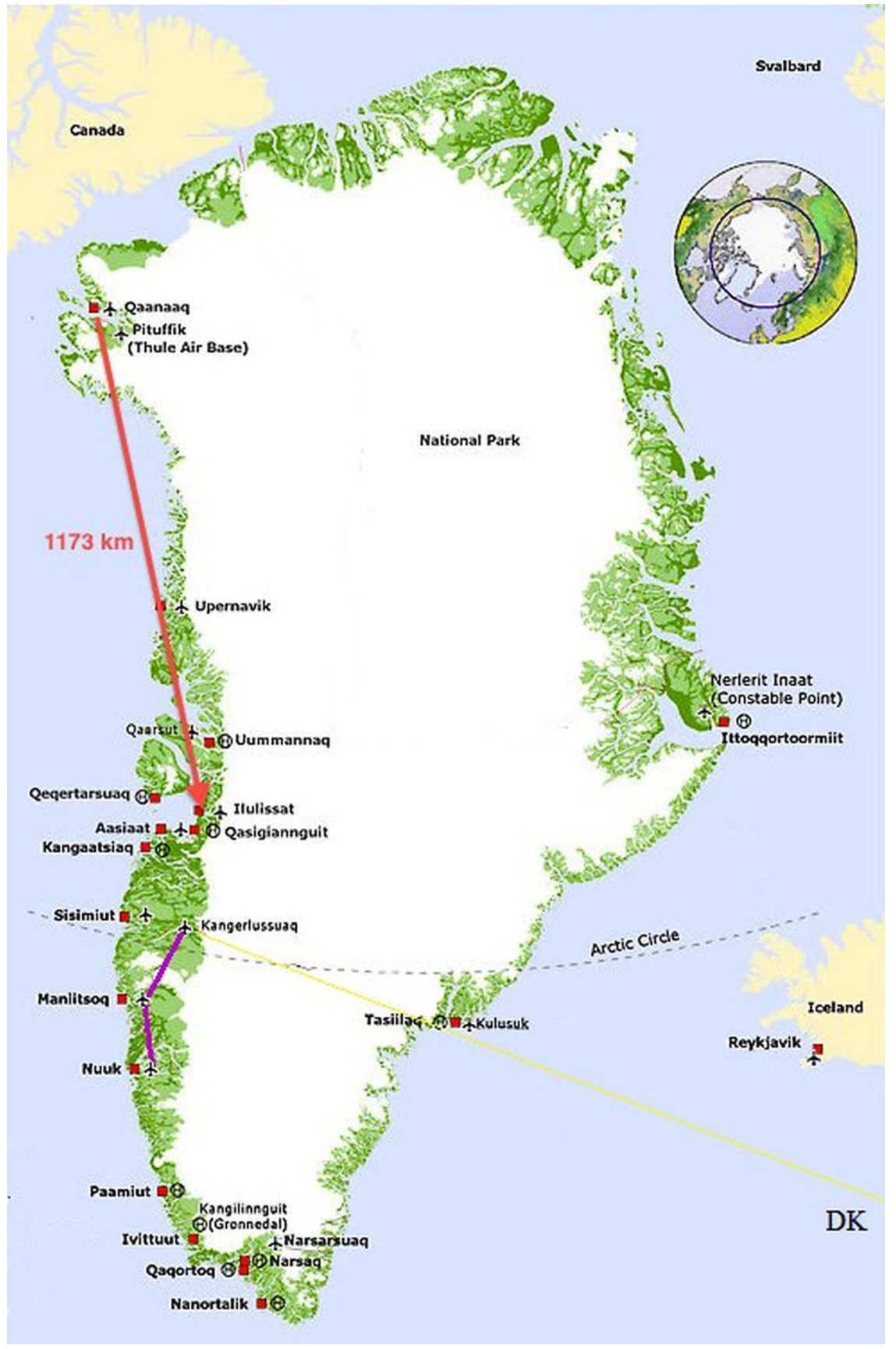

patients who have started antibiotic treatment but who require surgery because their symptoms do not resolve, does not cause an increase in complications. ${ }^{12}$

Antibiotic treatment has been proposed as a valuable treatment option for adult patients with acute appendicitis in remote areas, where no surgical care is available. ${ }^{3}$ Appendicitis occurs with the highest incidence in the second to third decade of life, hence it is not uncommon that appendicitis occurs during pregnancy. ${ }^{4} 5$ The question arises as how best to treat pregnant women who develop acute appendicitis and who live in a remote area where no surgical care is available. In the present case, we treated a pregnant patient with acute appendicitis, using intravenous antibiotics as a bridge-to-surgery. Clinical, laboratory and ultrasonography investigation and re-evaluation took place when the patient arrived at the hospital where surgical care could be provided, and the diagnosis of acute appendicitis was confirmed. Based on this, open appendicectomy was performed. Probably, some pregnant patients undergoing acute appendicitis treatment with intravenous antibiotics may be completely cured of signs and symptoms of acute appendicitis, and the need for surgical treatment might therefore not be necessary, as occurs in non-pregnant adults.

Appendicectomy can be performed either as an open or a laparoscopic procedure. ${ }^{6}$ In remote areas, laparoscopic equipment might not be available. A systematic review with meta-analyses including 11 studies with 3415 patients has looked at the harm and benefits of laparoscopic versus open appendicectomy during pregnancy. No differences were found regarding wound infection, birth weight, duration of operation or Apgar score. However, a nearly twofold risk for fetal loss was associated with laparoscopic surgery. ${ }^{6}$ Currently, we still prefer open appendicectomy during all stages of pregnancy until firm evidence shows that laparoscopic appendicectomy is not inferior to open appendicectomy regarding fetal loss. 
In conclusion, appendicitis during pregnancy is a serious disease that might be difficult to diagnose. Delay in diagnosis and treatment of appendicitis during pregnancy increases the risk of complications, including preterm birth and fetal loss. The present case shows that antibiotic treatment might be

\section{Learning points}

- Access to surgical care is not always available in remote areas.

- Access to surgical care can be delayed in remote areas due to large geographical distances and extreme weather conditions, which create the need for alternative treatment options either as a definitive treatment or as a bridge-to-surgery.

- Antibiotic treatment is a valuable alternative treatment option in adults with uncomplicated appendicitis, and the present case shows that antibiotic treatment might be applied as a bridge-to-surgery in pregnant women with appendicitis. applied as a bridge-to-surgery in pregnant women with appendicitis in remote areas where surgical care is not instantly available.

Competing interests None declared.

Patient consent Obtained.

Provenance and peer review Not commissioned; externally peer reviewed.

\section{REFERENCES}

1 Varadhan KK, Neal KR, Lobo DN, et al. Safety and efficacy of antibiotics compared with appendicectomy for treatment of uncomplicated acute appendicitis: meta-analysis of randomised controlled trials. BMJ 2012;344:e2156.

2 Wilms IM, de Hoog DE, de Visser DC, et al. Appendectomy versus antibiotic treatment for acute appendicitis. Cochrane Library. Issue 11. 1-39.

3 Campbell MR, Johnston SL III, Marshburn T, et al. Nonoperative treatment of suspected appendicitis in remote medical care environments: implication for future spacefight medical care. J Am Coll Surg 2004;198:822-30.

4 Penninga L, Penninga IE. Appendicitis during pregnancy; a serious disease and a diagnostic problem. In: Canfield R. ed. 'infectious pregnancy complications'. Nova Science Publishers, 2009.

5 Penninga L, Wettergren A. Perforated appendicitis during near-term pregnancy causing necrotizing fasciitis of the lower extremity: a rare complication of a common disease. Acta Obstet Gynecol Scand 2006;85:1150-1.

6 Wilasrusmee C, Sukrat B, McEvoy M, et al. Systematis review and meta-analysis of laparoscopic versus open appendicectomy for suspected appendicitis in pregnancy. Br J Surg 2012;99:1470-8.

Copyright 2016 BMJ Publishing Group. All rights reserved. For permission to reuse any of this content visit http://group.bmj.com/group/rights-licensing/permissions.

BMJ Case Report Fellows may re-use this article for personal use and teaching without any further permission.

Become a Fellow of BMJ Case Reports today and you can:

- Submit as many cases as you like

- Enjoy fast sympathetic peer review and rapid publication of accepted articles

- Access all the published articles

- Re-use any of the published material for personal use and teaching without further permission

For information on Institutional Fellowships contact consortiasales@bmjgroup.com

Visit casereports.bmj.com for more articles like this and to become a Fellow 